\title{
Using the Comfortability-in-Learning Scale to Enhance Positive Classroom Learning Environments
}

\author{
Michael Kiener, PhD, CRC \\ School of Health Professions \\ Maryville University \\ Peter Green, PhD \\ College of Arts and Sciences \\ Maryville University \\ Kelly Ahuna, PhD \\ School of Education \\ Medaille College
}

\begin{abstract}
A goal of higher education is to advance learning. This study examined the role "comfortability" plays in that process. Defined as the level of comfort students experience with their classmates, instructor, and course material, comfortability addresses how secure a student feels in the classroom. Comfortability was assessed multiple times during one semester with undergraduate students and found student comfortability significantly increased across the course of the semester and significantly predicted affective learning. These findings suggest the importance of the classroom environment in the learning process and support the need for faculty to consider "non-academic" factors in addition to course content.
\end{abstract}

Constructs such as engagement, community, relatedness, and connection are common in higher education. Multiple studies have demonstrated when students were more engaged, aware, and comfortable with their environments they would become more active in their learning (Tinnesz, Ahuna, \& Kiener, 2006), had a positive perception of learning and performance (McKinney, McKinney, Franiuk, \& Schweitzer, 2006) and persisted until graduation (Cheng, 2004; Harris, 2003). There are at least two underlying themes among these constructs that support positive learning environments, intellectual safety and affective learning. Schrader (2004) defined intellectual safety as a learning atmosphere in which students feel secure in challenging and strengthening ideas to deepen learning. Affective learning examines student intrinsic and extrinsic motivation, methods students use to interact with content, and how students receive, respond to, and integrate information to form an intellectual disposition (Delcourt, Cornell, \& Goldberg, 2007; Holt \& Hannon, 2006). It is feasible to believe a further examination of the interaction of intellectual safety or learning environment and affective learning will lead to additional insights on emphasizing student learning.

Rodríguez, Plax, and Kearney (1996) sought to analyze the indirect relationship between instructor nonverbal immediacy and cognitive learning; specifically examining if affective learning or student motivation had a more significant impact on cognitive learning. Examples of instructor nonverbal immediacy include: smiling, eye contact, and forward body lean. The researchers used a correlational design with path coefficients to determine which model (motivational or affective learning) had a greater fit to predict cognitive learning. The results of the study found when instructors displayed immediacy both student motivation and affective learning predicted cognitive learning; however, the affective learning model produced less error and thus had more theoretical relevance (Rodríguez et al., 1996). In addition to nonverbal instructor communication predicting affective learning, Henning (2010) examined the impact communicative style and instructor credibility had on student affective learning. Communicative style refers to how an instructor initiates, adapts, and responds to communication of others; whereas, instructor credibility is student evaluation and 
attitude towards his or her instructor. The study employed 279 undergraduates and found communicative style and instructor credibility predicted affective learning. The findings from these studies expand the importance of verbal and nonverbal communication on learning environments and affective learning.

Sidelinger, Bolen, Frisby, and McMullen (2011) investigated how negative instructor behaviors (being rude, insulting or sarcastic) impacted student connectedness and affective learning with 187 undergraduate communication students. The authors found when students developed a sense of connection to each other, negative instructor behaviors did not alter student course engagement. However, instructor misbehaviors did inhibit affective learning toward the instructor and course

\section{...when students perceived instructors to exhibit positive communication behaviors they had more positive student communication behaviors and outcomes.}

content. Student connectedness and affective learning was also examined by Johnson (2009) with 197 undergraduate students. The researcher found when students perceived they were connected with each other it predicted affective learning, specifically intent to enroll in similar courses and to engage in ideas discussed in the course. This research speaks to the importance of students creating an environment to benefit their learning and how their engagement can override negative instructional behaviors.

Similarly, instructors can also positively impact the learning environment. Mazer and Hunt (2008) studied the effects of instructor positive and negative slang on affective learning, motivation, and classroom climate with 175 undergraduates. Positive slang was informal language used to engage with students whereas negative slang was verbal obscenities deemed inappropriate by students. The researchers found positive and no slang communication had similar effects on affective learning and motivation, but negative slang had a significant negative impact on classroom climate. Goodboy and Myers (2008) investigated how instructor communication behaviors impacted cognitive and affective learning. Positive communication behaviors include eye contact, head nodding, and acknowledging responses; whereas negative communication behaviors include interrupting, avoiding, and discrediting answers. The researchers found when students perceived instructors to exhibit positive communication behaviors they had more positive student communication behaviors and learning outcomes. Adding to the students' role in creating positive learning environments, instructor verbal and nonverbal behaviors can be emphasized to benefit learning.

Arguably, increasing a sense of community and affective learning may have significant importance in professional programs where students are taught to create therapeutic environments to benefit practice. Moreover, Shulman described professional education as more than an academic process and stated,

( $\mathrm{T}$ ) o become a professional, one must learn not only to think in certain ways but also to perform particular skills, and to practice or act in ways consistent with the norms, values, and conventions of the profession. (2004, pp. 67-68)

In other words, affective learning has an important role in developing a professional worldview and disposition.

Based on this evidence it would be difficult to ignore the role positive learning environments have on higher education as a means of increasing student affective learning. As a result it would be advantageous for instructors to investigate individual courses and programs to maximize the potential of positive learning environments. However, for many faculty members, studying one's teaching to improve learning is a new endeavor (Huber \& Hutchings, 2005).

The scholarship of teaching and learning (SoTL) is a natural fit as a philosophy for instructors to study their teaching, student learning, and documenting outcomes. SoTL views the classroom as a research site and calls for 
rigorous methodology to review and improve teaching and student learning (Huber \& Hutchings, 2005).

As with other forms of scholarship, SoTL requires a question to be investigated, data to be collected and analyzed, and findings to be implemented. An equally important SoTL theme is making quality teaching public for others to critique and build theory (Huber \& Hutchings, 2005).

In an attempt to expand the value of identifying positive learning environments, the Comfortability in Learning Survey (CLS) was created (Kiener, Green, Ahuna, \& McCluskey, 2013). Comfortability emerged as a core category in a grounded theory study designed to better understand how counseling students learn and is conceptualized as a dual process students and instructor employ to form a positive learning environment (Kiener, 2007). Comfortability is defined as the level of comfort students experience with their classmates, instructor, and course material. Moreover, comfortability is related to student self-efficacy in their learning and ability to complete coursework. When students and instructors establish comfortability students have the capability to become more active in their learning and integrate information that may have been perceived as difficult or challenging prior to the start of the course (Kiener et al., 2013). Allowing students to provide feedback regarding how they best learn and in creating assignments is one avenue to increase the capacity of comfortability.

An assumption with the CLS is when students are asked to overtly rate their comfortability they have the potential to become more aware and active in their learning. One goal in the creation of the CLS was to provide a tool of ongoing assessment that instructors could administer in their own classrooms with resulting data that could be used to improve and document student learning.

Perhaps the greatest potential of the CLS is administering it multiple times in a single course or across multiple courses in a program to measure the development (or non-development) of comfortability. Based on the results of each administration, instructors can make pedagogical changes to improve teaching and learning. In addition, results can be shared with students for another opportunity for them to "see" their comfortability in learning and provide feedback to students and instructor.

Thus, the purpose of this study was to extend the utility of the CLS as a program measure. By administering the CLS multiple times in a professional program, data can be analyzed to better collectively gauge students' comfortability in learning. A secondary purpose was to investigate if scores on the CLS could predict affective learning. Increasing affective learning in professional programs is instrumental because students will not only have to think but also act and behave as professionals. Therefore, the research questions for this study were: 1) Would comfortability significantly increase over the course of the semester; 2) Would scores on the CLS significantly predict affective learning toward content and instructor; and 3) Would questions seven, 15, and 16 on the CLS significantly increase over the course of the semester. The three questions were: "The instructor in this class uses assessment procedures that are appropriate to demonstrate student learning"; "I use information from this class in other situations (other classes or field experiences)"; and "Material in this class that initially may have seemed challenging has become more understandable over time." These questions were chosen because of the potential to provide evidence of student comfortability with thinking about and applying course content.

\section{Methodology}

A quantitative methodology was used to answer the research questions. This methodology was appropriate because it allowed the researchers to measure the construct under investigation and demonstrates the potential usefulness of collecting and analyzing multiple administrations of the CLS throughout the semester to improve the learning environment. 


\section{Participants \& Courses}

Four faculty members in the School of Health Professions agreed to distribute the CLS to their undergraduate students during the spring 2013 semester. Out of 46 students in five courses, a total of 26 individual students consented to participate in the study. Twelve students were enrolled in more than one course and 14 students were enrolled in one course. Three students were enrolled in four courses, two students were enrolled in three courses, and seven students were enrolled in two courses. All of the students were undergraduates from a private Midwestern liberal arts university. Thirty-three students were majors in the rehabilitation services program and 13 were non-rehabilitation services majors. There were a total of 18 students in the rehabilitation services' major. The other majors included psychology, occupational therapy, and students who were undeclared. The average age of the students was 22 with a range from 17- 41. All of the students were female except for one, and all students were Caucasian except for one who identified as African American. These demographics were representative of students in this program at this university. Seventeen students had prior experience with their instructor. All of the courses chosen for this study were in the rehabilitation services program and were taught by full-time faculty. Three of the faculty members taught one course and one faculty member taught two courses. The courses consisted of one 200 level, one 300 level, and three 400 level courses. Rehabilitation services is a human service profession and rehabilitation service providers work with individuals with disabilities to secure employment, live independently, and gain full inclusion into society.

\section{Procedure \& Measures}

In weeks four, eight, and 12 of the semester participants completed the Comfortability in Learning Scale (Kiener et al., 2013) and the Instructional Affect Assessment Instrument (McCroskey, 1994). The CLS is a 20-item survey asking students to rate their comfort with their classmates, instructor, and course content. Questions are answered on a five point Likert scale ranging from totally disagree (1) to totally agree (5). Sample questions include: "Classmates in this class often help each other in understanding difficult material"; "The instructor has created a respectful environment to share ideas in this class"; and "Material in this class that initially may have seemed challenging has become more understandable over time". The CLS has more than adequate reliability; Cronbach's Alpha range from .863-.933 and split half coefficients range from .811-.908. The CLS has a criterion validity coefficient of .737 and strong face and content validity (Kiener et al., 2013). The Instructional Affect Assessment Instrument has two eight-item scales measuring affect for content and affect for instructor. Reliability coefficients range from .85.90 and has sound face and predictive validity (McCroskey, 1994).

After each administration, data were analyzed by the first author and presented to the other participating instructors as a method of ongoing assessment. Group and individual data were presented and individual course data were only seen by the first author and by the instructor teaching the course. The first author was also available to discuss the results individually with each instructor. As a method to increase comfortability, the first author shared the results of his survey at each administration with his students and allowed them to ask questions and make their own interpretations of the data to help improve teaching and learning.

\section{Results}

To address the first research question, would comfortability increase over the course of the semester, a repeated measures ANOVA was conducted on the CLS across the three time periods. Results indicated a significant increase from week 1 to week $4, F(2,54)=4.23, p=.02, n p 2=.135$. A follow-up analysis showed an increase in comfortability from week four $(M=4.24$, $S D=.51)$ to week eight $(M=$ 
4.37, SD $=.50)$, and from week four to week $12(\mathrm{M}=4.42, \mathrm{SD}=.60)$, but no significant difference between week eight and week 12 .

To determine if comfortability predicted affective learning toward content and instructor, correlations were initially analyzed to determine if a relationship existed. The researchers examined the final time period ( 12 Weeks) as the second research question was interested in determining whether comfortability, as it developed over the course of a semester, predicted affective learning at the end of the class. CLS was significantly correlated with both affective learning toward content $(r(39)=.709, p<.001)$, and toward instructor $(r(39)=.750, p<.001)$. Simple linear regression analyses indicated significant prediction of affective content ( $\mathrm{t}=6.12, \mathrm{p}<.001$ ), accounting for $50.3 \%$ of the overall variance. CLS also significantly predicted affect toward instructor, $(t=6.89), p<.001$, accounting for $56.2 \%$ of the overall variance.

Repeated measures ANOVAs were conducted on the three individual CLS questions to determine if any increase in frequency occurred during the semester. Results indicated very little change in these specific questions. Any differences over the semester for items seven (The instructor in this class uses assessment procedures that are appropriate to demonstrate student learning) and 15 (I use information from this class in other situations [other classes or field experiences]) were clearly not significant, F's $<1.0$. Item 16 (Material in this class that initially may have seemed challenging has become more understandable over time.) did show a marginal increase, $\mathrm{F}(2,54)=2.74, \mathrm{p}=.074, \mathrm{np} 2=.092$. Follow-up analyses indicated the only significant increase occurred between week $4(M=3.96$, $\mathrm{SD}=.74)$ and week $12(\mathrm{M}=4.25, \mathrm{SD}=.84)$ for question 16.

\section{Discussion}

The purpose of this study was to expand the use of the CLS by administering it multiple times throughout a semester to better track factors that contribute to comfortability and affective learning. By assessing the CLS multiple times and analyzing the data it provided an opportunity for instructors to have a method of ongoing assessment to monitor their courses, increase student awareness of their learning environment, and make changes to enhance learning. By examining multiple courses within one program it allowed for a more comprehensive assessment of the program's comfortability and affective learning.

The results indicated that comfortability

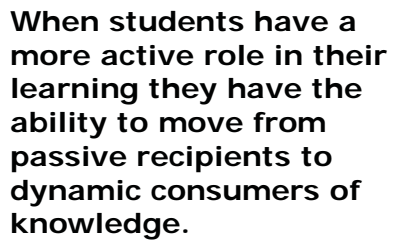
implement strategies to monitor and enhance the learning environment. When students have a more active role in their learning they have the ability to move from passive recipients to dynamic consumers of knowledge (Tinnesz, Ahuna, \& Kiener, 2006). Students' perception of comfortability did significantly predict affective learning (affect for instructor and affect for content). It is possible when students increase their affective learning they are developing learning characteristics such as enthusiasm, persistence, and curiosity (Ahuna \& Tinnesz, 2006). Moreover, because affective learning deals with attaining positive attitudes toward a teacher and or subject, it is plausible to believe students were developing an increased mindset toward their profession (Rodríguez et al., 1996).

As for the third research question, two out of the three individual questions (seven \& 15) did not show a significant increase through the semester and the remaining question (17) had a significant increase only between weeks four and 12 . A closer examination of all the means over the administrations indicate a low mean of 3.97 (question six first administration) and a high mean of 4.37 (question 15 first administration). Based on these scores, it is feasible to conclude students felt

Volume $9 \bullet 2014$ 
comfortable throughout the semester with classmates helping each other with difficult material, using information in other situations, and difficult material becoming more understandable over time. In total, these results indicate the benefit of using an assessment, such as the CLS, as a means of ongoing assessment to monitor the learning environment and inform teaching and student learning.

\section{Future Research \& Limitations of the Study}

Additional research would benefit from further examination of demographic differences between students and instructors. For example, will comfortability develop differently for non-majors and students without prior experience with instructors compared to students who are majors and with students who have prior experience with instructors? Repeating this

Teaching is an art as opposed to a science.

study with multiple programs may reveal differences in how programs view learning environments as a means to increase learning. It would also be interesting to investigate how instructors could implement changes to courses based on data from each administration of the CLS. Adding open ended questions to the CLS for students and instructors may shed additional insight on learning. Students could be asked to describe how their comfortability with classmates, instructor, and course content changed throughout the semester and instructors could be asked to describe how they used the data form the CLS to inform their teaching.

Although the results are representative of the programs' students, and possibly other human services programs at small liberal arts institutions, the small sample size does decrease the study's external validity to a broader population. Increasing the diversity of the students, programs, and institutions would help generalize the value of using the CLS as a learning outcome measure. In addition, without a comparison group, it is difficult to state for certain that the effects were the result of the program's sense of comfortability and not another external factor causing the change.

\section{Application to a Broader Audience}

Adding to the milieu of higher education is the rising demand for institutions to be accountable and demonstrate student learning outcomes. Accrediting agencies are requiring institutions to do a better job of identifying, tracking, and demonstrating student outcomes. Institutions that implement a culture of assessment and use data to improve teaching and learning will have a distinct advantage in attracting and graduating students.

Regardless of academic area, these findings exemplify the positive benefit of creating a secure classroom environment. Particularly in health and human service fields in which students will become future professionals servicing the community, it is imperative to maximize learning. This research shows that increased comfortability leads to increased affective learning. As a result, students get more from their classes and the community gets more from its professionals. Teaching is an art as opposed to a science. Instructors at all levels can continually improve their practice, and a new attention to comfortability is one facet that can be addressed.

\section{Conclusion}

This study sought to better understand if student perception of a positive learning environment could be developed in a rehabilitation services program over the course of a semester and if a positive learning environment could predict affective learning. The results indicated a sense of comfortability did increase in the program, and comfortability did predict affective learning. Increasing affective learning for students in professional programs has the potential to indicate students are transitioning to their new professional roles. One of the strengths of the study 
is embracing ongoing assessment to improve instruction and student learning. When instructors collect data on their teaching and student learning they have the ability to better demonstrate they are achieving student learning outcomes.

\section{References}

Ahuna, K. H., \& Tinnesz, C. G. (2006). Methods of inquiry applied critical thinking ( 2 nd ed.). Dubuque, IA: Kendall/Hunt.

Cheng, D. X. (2004). Students' sense of campus community: What it means, and what to do about it. NASPA J ournal, 41, 216-234.

Delcourt, M. A. D., Cornell, D. G, \& Goldberg, M. D. (2007). Cognitive and affective learning outcomes of gifted elementary school students. The Gifted Child Quarterly, 51, 259282.

Goodboy, A. K., \& Myers, S. A. (2008). The effect of teacher confirmation on student communication and learning outcome. Communication Education, 57, 153-179.

Harris, B. A. (2003). The power of creating a spiritual learning community. Adult Learning, 12, 2223.

Henning, Z. (2010). Teaching with style to manage students perceptions: The effects of sociocommunicative style and teacher credibility on student affective learning. Communication Research Reports, 27, 58-67.

Holt, B. J., \& Hannon, J. (2006). Teaching-learning in the affective domain. Strategies, 20, 11-13.

Huber, M. T., \& Hutchings, P. (2005). The advancement of learning building the teaching commons. San Francisco, California: Jossey-Bass.

Johnson, D. I. (2009). Connected classroom climate: A validity study. Communication Research Reports, 26, 146-157.
Kiener, M. S. (2007). Scholarship of teaching in rehabilitation counseling practicum. Rehabilitation Education, 21, 169-178.

Kiener, M. S., Green, P., Ahuna, K., \& McCluskey, J. (2013). Creation of the comfortability in learning scale. Transformative Dialogue: Teaching and Learning J ournal, 6(3). Retrieved from http://www.kpu.ca/td/past-issues/6-3

Mazer, J.P., \& Hunt, S. K. (2008). The effects of instructor use of positive and negative slang on student motivation, affective learning, and classroom climate. Communication Research Reports, 25, 44-55.

McCroskey, J.C. (1994). Assessment of affect towards communication and affect toward instruction in communication. In S. Morreale \& M. Brooks (Eds.), 1994 SCA summer conference proceedings and prepared remarks: Assessing college students competence in speech communication. Annandale, VA: Speech Communication Association.

McKinney, J. P., McKinney, K. G., Franiuk, R., \& Schweitzer, J. (2006). The college classroom as a community. College Teaching, 54, 281-284.

Rodríguez, J. I., Plax, T. G., \& Kearney, P. (1996). Clarifying the relationship between teacher nonverbal immediacy and student cognitive learning: Affective learning as the central causal mediator. Communication Education, 45(4), 293-305.

Schrader, D. E. (2004). Intellectual safety, moral atmosphere and epistemology in college classrooms. J ournal of Adult Development, 11, 87-101. 
Shulman, L. S. (2004). Teaching as community property essays on higher education. San Francisco, CA: JosseyBass.

Sidelinger, R. J., Bolen, D. M., Frisby, B. N., \& McMullen A. L. (2011). When instructors misbehave: An examination of student-to-student connectedness as a mediator in the college classroom. Communication Education, 60, 340-361.
Tinnesz, C. G., Ahuna, K. H., \& Kiener, M. (2006). Toward college success: Internalizing active and dynamic strategies. College Teaching, 54, 302306.

Michael Kiener is an associate professor and director of the Rehabilitation Counseling and Services programs. Michael has co-authored a book on strength based counseling, published articles on career decision making, active and dynamic learning strategies, counseling pedagogy, and action research. In 2012 he received the Outstanding Faculty Award and the President's Award for Strategic Excellence: Civic Engagement from Maryville University.

Peter J. Green is the Assistant Dean of Social Sciences, Program Director and Associate Professor of Psychology at Maryville University St. Louis. In addition to conducting research related to the Scholarship of Teaching and Learning, he also interested in exploring social norms in two distinct fields. The first examines the impact these norms, often incorrect, have on the health-related behaviors and attitudes of college students, including alcohol consumption and safe sex. The second explores the role social norms may have in biases that permeate the criminal justice system.

Kelly $\mathrm{H}$. Ahuna is Program Director of the MSED Adolescent and Elementary Education Programs at Medaille College where she helps to prepare future teachers. She holds a bachelor's degree in English with secondary teacher certification from Dickinson College, a master's degree in higher education administration from the University of Vermont and a doctoral degree in sociology of education from the University at Buffalo. Prior to her work at Medaille, Dr. Ahuna ran an undergraduate critical thinking program for ten years. Her interests lie at the intersection of teacher and learner effectiveness. 